\title{
Oncology Critical Care Nurse's Knowledge about Insertion, Care and Complications of Venous Port Catheters in Egypt
}

Khalil NS*, Youssef W and Moustafa Z

Critical Care and Emergency Nursing, Faculty of Nursing Cairo University, Egypt

${ }^{*}$ Corresponding author: Nahla Shaaban Khalil, Critical care and Emergency Nursing, Faculty of Nursing Cairo University, Egypt, Tel: +20 2 23657190;E-mail: nahlakhalil28@yahoo.com

Received date: June 14, 2017; Accepted date: June 27, 2017; Published date: July 4, 2017

Copyright: (C) 2017 Khalil NS, et al. This is an open-access article distributed under the terms of the Creative Commons Attribution License, which permits unrestricted use, distribution, and reproduction in any medium, provided the original author and source are credited.

\begin{abstract}
Implantable port catheter devices are frequently used to manage patients undergoing long term administration of chemotherapy. Though it has many advantages, they are not free from complications. Nurse's who are knowledgeable and competent in the basic aspects of port-a-cath care able to ensure specific child needs are met and prevent further complications. Aim: was to assess Oncology Critical Care Nurse's Knowledge about insertion, Care and Complications of Venous Port Catheters in Egypt. Research Design: A descriptive design was utilized. Setting: was conducted at critical care units at 57357 hospitals in Egypt. Subject: A convenient sample of 100 oncology nurses who cared for patients undergoing port-a-cath insertion were enrolled in this study. Tools: nurse's background and implantable port catheter care knowledge questionnaire were utilized. Results: In this study, $62 \%$ of oncology nurses received in-service training courses about the implantable port catheter. Also, it revealed two thirds of the studied subjects (69\%) have got satisfactory knowledge level with the average mean $40.31+2.12$ out of 50 . Moreover, it showed high significant differences among the oncology nurses level of knowledge by their age and educational qualifications and total knowledge scores $\left(X^{2}=13.17, p=0.001\right.$ and $X^{2}=7.79, p=0.02$ respectively), nurses' years of experience in nursing profession, experience in handling port-a-cath, attending training courses about port-a-cath $\left(X^{2}=23.48, p=0.0001 ; X^{2}=20.89, p=0.0001\right.$ and $X^{2}=55.47, p=0.0001$ respectively. Conclusion: The majority of the oncology nurses had got satisfactory level and there was significant correlation between the nurses' knowledge level and their demographic characteristics except their gender. Recommendations: periodic consideration of in-service training programs regarding port-a-cath implantation care according to the updated standards and guidelines.
\end{abstract}

Keywords: Oncology; Nurse's knowledge; Implantable; Port catheter; Care

\section{Introduction}

Central Venous Access Devices (CVADs) have been used successfully for over 40 years in a wide variety of settings. In the acute care setting they provide a route for rapid and reliable intravenous administration of drugs, fluids, blood products and Parenteral Nutrition (PN) and may be used to monitor Central Venous Pressure. They are also used for children who require long term IV access undergoing continuous/intermittent complex IV therapies such as chemotherapy and blood sampling and Parenteral Nutrition (PN) [1]. Children with cancer and other illnesses may require intravenous/ cytotoxic therapy over a long period. Insertion of a central venous line will enable them to receive treatments such as chemotherapy, total parental nutrition, blood products, fluids, medications and blood sampling without the need for multiple venipuncture's [2].

Long-term central venous catheters (CVCs) have been in clinical use for over 20 years for the administration of infusional cytotoxic therapy to children with both haematological and solid malignancies. This practice is increasing rapidly due to ease of catheter insertion, novel high dose chemotherapy regimens requiring long term vascular access and increased use of ambulatory infusional regimens [3].

Most long-term devices used in the cancer setting are made from silicone or polyurethane. Silicone is a soft, biocompatible material.
Catheters made from silicone provide benefits for the child as the material reduces the adherence of fibrin to the catheter and offers increased biocompatibility. Polyurethane is a stronger, firmer material, which allows the walls of the CVAD to be thinner while still providing the same lumen diameter [4].

Totally implantable ports are accepted as a safe and effective method of facilitating long-term intravenous therapy. These devices were first introduced in the early 1980's and used as a form of venous access in oncology children. Ports are now also commonly used in children with cystic fibrosis requiring long-term intravenous antibiotics because of their low complication rates [5]. A port is similar to a tunneled catheter but is left entirely under the skin. Medicines are injected through the skin into the catheter. Implanted ports contain a small reservoir that can be refilled in the same way. After being filled, the reservoir slowly releases the medicine into the bloodstream. An implanted port is less obvious than a tunneled catheter and requires very little daily care. It has less impact on a person's activities than a PICC line or a tunneled catheter [6]. Central line bundle includes five components: hand hygiene, maximal barrier precautions, chlorhexidine $2 \%$ skin antisepsis, optimal catheter site, and daily review of line necessity with prompt removal of unnecessary lines. The power of a bundle is that it brings together those scientifically grounded concepts that are both necessary and sufficient to improve the clinical outcome of interest. The focus of measurement is the completion of the entire bundle as a single intervention, rather than completion of its individual components [7]. Nurse requires specific education and training to attain the knowledge, assessment skills and 
technical tasks required to manage the care for children who have port-a-cath. Nurses who are knowledgeable and competent in the basic aspects of port-a-cath care and maintenance are able to ensure specific child needs are met and optimal health outcomes achieved. However, nurse's who work in oncology require a higher level of knowledge and skill to manage port-a-cath [8].

\section{Aim of the Study}

The aim of this study was to assess oncology critical care nurse's knowledge about insertion, care and complications of venous port catheters in Egypt.

\section{Research Question}

What do oncology critical care nurses' know about insertion, care and complications of venous port catheters in Egypt?

\section{Research Design}

A descriptive cross sectional was utilized in the current study. This design was adopted because it records information about the studied subjects without manipulating the study environment at a defined time. Moreover, Descriptive or exploratory studies are used when little is known about a particular phenomenon the researcher describes, and documents various aspects of a phenomenon. There is no manipulation of variables or search for cause and effect related to the phenomenon. Descriptive designs describe what actually exists, determine the frequency with which it occurs, and categorizes the information [9].

\section{Subjects}

A sample of convenience of 100 males and females oncology nurses who cared for patients undergoing port-a-cath insertion were recruited randomly, their age ranges between $21-45$ year. The minimum years of experience were at least 3 years and their educational level were varied

\section{Setting}

The study was conducted at 57357 hospitals. That hospital is a large governmental pediatric oncology hospital in Egypt provides a variety of free health services to cancer children. This hospital includes a large number of pediatric units that provide the oncology children with different medical and surgical interventions needed; these units are medical, surgical, intensive care unit, operating room, emergency and day care unit.

\section{Tools}

Two tools were utilized to collect data pertinent to the current study.

\section{Oncology nurses' demographic data}

It included data related to gender, age, educational level, area of work, and years of experience in pediatric oncology units.

\section{Port-A cath knowledge questionnaire}

It was developed by researchers to assess nurse's knowledge about port-a-cath. It included 25 questions that covered definition of port-acath, indication, complications, contraindications of port-a-cath, preparation, infection control measurements, patent education, regulation of port-a-cath and heparinzation care of port a cath.

\section{Scoring system}

The total score for the questionnaire was 50 grades; each right answer took one grade. The scoring system classified as follows;

- Scores less than $37.5(<75 \%)$ was unsatisfactory.

- Scores equal or more than 37.5 ( $\geq 75)$ were satisfactory

\section{Validity and reliability}

Content validity was done to identify the degree to which the used tools measure what was supposed to be measured. Tools developed by the investigator were examined by a panel of five experts in oncology medicine, critical care and oncology nursing to determine whether the included items are clear and suitable to achieve the aim of the current study. The designed knowledge questionnaire was reliable utilizing inter rater reliability with kappa coefficient $=0.79$.

\section{Ethical consideration}

Permission to conduct the proposed study was obtained from the administrative authorities of 57357 Hospital, which is affiliated by the government. Later, during the phase of data collection, all participants informed about the purpose and nature of the study in order to obtain their acceptance to participate in the study. In addition, the researcher emphasized to each interview that participation in the study was voluntary. Moreover, anonymity and confidentiality were assured through the coding of data and all obtained information was secured and wouldn't affect their annual appraisal.

\section{Pilot study}

A pilot study was carried out on 10 nurses to test feasibility, objectivity, and applicability of the study tools. Carrying out the pilot study gave the investigator experience to deal with the included subjects, and the data collection tools. Based on the results of the pilot study, no modifications were done and pilot study subjects were included in the present study.

\section{Procedure}

The current study was carried out through two phases; designing phase, implementation and evaluation phases.

\section{Designation phase}

Designation included the construction and preparation of data collection tools after extensive review of literatures, previous studies, web site searches, and seeking expert's advice. Then, data collection tools were reviewed by a panel of oncology medicine and oncology nursing to ensure content validity. In addition, the managerial arrangements were sought to carry out the study by clarifying the purpose and the nature of the study to gain their cooperation. A pilot study was carried out on six nurses working in the selected Critical Care units to test the feasibility, objectivity, and applicability of the study tools. Based on the results of the pilot study, needed refinement/ modifications were made in the data collection instruments. 
Citation: Khalil NS, Youssef W, Moustafa Z (2017) Oncology Critical Care Nurse's Knowledge about Insertion, Care and Complications of Venous Port Catheters in Egypt. Adv Practice Nurs 2: 137. doi:10.4172/2573-0347.1000137

Page 3 of 5

\section{Implementation phase}

Once official permissions were granted, the researcher visited the mentioned selected oncology paediatric units on a daily basis during morning shift. Each potential nurse was contacted and interviewed for 45-60 minutes to fill out the background data sheet and the knowledge questionnaire pertinent to port-a-cath. During which, the researcher is accessible to clarify any obscure questions.

\section{Statistical analysis}

Upon completion of data collection, data were tabulated and analyzed using statistical package for social sciences (SPSS) program version 20. Relevant statistical analysis was done to test the obtained data. Descriptive and inferential statistics were performed such as mean and standard deviation; frequency; percentage and correlation coefficient. The level of significance was considered at the $5 \%$ level $(\mathrm{P}=0.05)$.

\section{Results}

Table 1 illustrates the demographic characteristics of the studied subjects. As can be seen from the Table 1 that the majority of the studied nurses were females $(67.0 \%)$ and baccalaureate graduates (65\%). Half of studied nurses (50.1\%) their age ranged between 25-30 years with the mean age $27.23 \pm 3.61$ years. Regarding years of experience in nursing field, half of the study subjects (55.0\%) were having 9-12 years of experience the nursing field with the mean 10.91 \pm 2.76 years, and $39.0 \%$ of the study subjects were having more than nine years of experience in caring of Port-a-cath with the mean years of $10.12 \pm 2.31$. In addition, the majority of the studied nurses attended previous training courses regarding port- $\mathrm{A}$-cath insertion and care $(62.0 \%)$.

\begin{tabular}{|c|c|c|}
\hline \multirow{2}{*}{$\begin{array}{l}\text { Demographic Data } \\
\text { - }\end{array}$} & \multicolumn{2}{|c|}{ Study sample $N=100$} \\
\hline & Number & $\%$ \\
\hline \multicolumn{3}{|l|}{ Sex } \\
\hline Male & 33 & 33 \\
\hline Female & 67 & 67 \\
\hline \multicolumn{3}{|l|}{ Age in Years } \\
\hline$<25$ & 35 & 35 \\
\hline $25-30$ & 51 & 51 \\
\hline$>30$ & 14 & 14 \\
\hline \multicolumn{3}{|c|}{ Mean \pm SD $27.23 \pm 3.61$} \\
\hline \multicolumn{3}{|c|}{ Educational Qualifications } \\
\hline Bachelor & 65 & 65 \\
\hline Diploma & 23 & 23 \\
\hline Technical institute & 12 & 12 \\
\hline \multicolumn{3}{|c|}{ Years of Experience in Nursing } \\
\hline $5<9$ & 18 & 18 \\
\hline $9-12$ & 55 & 55 \\
\hline
\end{tabular}

\begin{tabular}{|l|l|l|}
\hline $13-15$ & 15 & 15 \\
\hline$>15$ & 12 & 12 \\
\hline Mean \pm SD $10.91 \pm 2.76$ & 27 & 27 \\
\hline Years of Experience with Port-a-cath & \multicolumn{2}{|l|}{} \\
\hline $3<6$ & 34 & 34 \\
\hline $6-9$ & 39 & 39 \\
\hline$>9$ & \multicolumn{2}{|l|}{} \\
\hline Mean \pm SD 10.12 \pm 2.31 & 62 & 62 \\
\hline Previous Training Courses & 38 & 38 \\
\hline Yes & \multicolumn{2}{|l|}{} \\
\hline No & 38 & 38 \\
\hline
\end{tabular}

Table 1: Percentage Distribution of oncology nurses' demographic characteristics $(\mathrm{N}=100)$.

Figure 1 presents the percentage distribution of the total knowledge level of the studied nurses about insertion and care of port-a-cath. It shows that the majority of the studied subjects (69.0\%) have got satisfactory knowledge level.

\begin{tabular}{|c|c|c|c|c|}
\hline \multicolumn{5}{|l|}{$\begin{array}{l}\text { - Unsatisfactory } \\
\text { - Satisfactory }\end{array}$} \\
\hline \multirow[t]{2}{*}{ Item } & \multicolumn{2}{|c|}{ Satisfactory } & \multicolumn{2}{|c|}{ Unsatisfactory } \\
\hline & No. & $\%$ & No. & $\%$ \\
\hline Definition of port-a-cath & 68 & 68.0 & 32 & 32.0 \\
\hline Indications of port-a-cath & 76 & 76.0 & 24 & 24.0 \\
\hline Local complications of port-a-cath & 69 & 69.0 & 31 & 31.0 \\
\hline General complications of port-a-cath & 72 & 72.0 & 28 & 28.0 \\
\hline port-a-cath insertion regulation & 62 & 62.0 & 38 & 38.0 \\
\hline Contraindications of port-a-cath & 68 & 68.0 & 32 & 32.0 \\
\hline
\end{tabular}

Table 2: Percentage distribution of satisfactory and unsatisfactory answers in relation to general knowledge about insertion and care of port-a-cath among oncology nurses $(\mathrm{N}=100)$. 
Table 2 shows the percentage distribution of satisfactory and unsatisfactory responses to knowledge questions related to port-a-cath care. It is clear from the table that most of the studied subjects have got the satisfactory responses in the following sub-items and distributed as follows; indication of port-a-cath $(76.0 \%)$, local complication of porta-cath $(69.0 \%)$, general complications for the port-a-cath $(72.0 \%)$ and the contraindications of port-a-cath $(68 \%)$. On the other hand more than one fourth of the subjects have got unsatisfactory responses regarding port-a-cath insertion regulation (38\%).

\begin{tabular}{|c|c|c|c|c|c|c|}
\hline \multirow[t]{3}{*}{ Items } & \multicolumn{4}{|c|}{ Knowledge } & \multirow{3}{*}{\begin{tabular}{|l|l}
$X^{2}$ \\
- \\
- \\
\end{tabular}} & \multirow{3}{*}{\begin{tabular}{|l|}
$\begin{array}{l}\text { P- } \\
\text { Value }\end{array}$ \\
- \\
- \\
\end{tabular}} \\
\hline & \multicolumn{2}{|c|}{ Satisfactory } & \multicolumn{2}{|c|}{ Unsatisfactory } & & \\
\hline & No & $\%$ & No & $\%$ & & \\
\hline \multicolumn{7}{|l|}{ Age } \\
\hline $20-24$ & 25 & 25.0 & 10 & 10.0 & - & - \\
\hline $25-29$ & 37 & 37.0 & 14 & 14.0 & 13.17 & 0.001 \\
\hline$\geq 30$ & 7 & 7.0 & 17 & 17.0 & - & - \\
\hline \multicolumn{7}{|l|}{ Gender } \\
\hline Male & 27 & 27.0 & 6 & 6.0 & 2.94 & 0.08 \\
\hline Female & 42 & 42.0 & 25 & 25.0 & - & - \\
\hline \multicolumn{7}{|l|}{ Qualification } \\
\hline Bachelor & 51 & 51.0 & 14 & 14.0 & - & - \\
\hline Diploma & 12 & 12.0 & 11 & 11.0 & 7.79 & 0.02 \\
\hline Technical institute & 6 & 6.0 & 6 & 6.0 & - & - \\
\hline \multicolumn{7}{|c|}{ Port-a-cath experience } \\
\hline $3-5$ & 24 & 24.0 & 3 & 3.0 & - & - \\
\hline $6-8$ & 29 & 29.0 & 5 & 5.0 & 23.48 & 0.0001 \\
\hline$\geq 9$ & 16 & 16.0 & 23 & 23.0 & - & - \\
\hline \multicolumn{7}{|c|}{ Experience in nursing } \\
\hline $5-8$ & 9 & 9.0 & 9 & 9.0 & - & - \\
\hline $9-12$ & 47 & 47.0 & 8 & 8.0 & 20.89 & 0.0001 \\
\hline $12-15$ & 10 & 10.0 & 5 & 5.0 & - & - \\
\hline$\geq 15$ & 3 & 3.0 & 9 & 9.0 & - & - \\
\hline \multicolumn{7}{|l|}{ Training } \\
\hline Yes & 60 & 60.0 & 2 & 2.0 & 55.47 & 0.0001 \\
\hline No & 9 & 9.0 & 29 & 29.0 & - & - \\
\hline
\end{tabular}

Table 3: Relationship between demographic characteristics of the oncology nurses and their total knowledge level regarding insertion and care of port-a-cath.

Table 3 shows the relationship between demographic characteristics of the oncology nurses and their total knowledge level regarding insertion and care of port-a-cath. It revealed that there was highly statistically significant correlation between demographic characteristics of the studied nurses and their total knowledge score about port-a-cath such as age $\left(\mathrm{X}^{2}=13.17, \mathrm{p}=0.001\right)$, educational level $\left(\mathrm{X}^{2}=7.79, \mathrm{p}=0.02\right)$,years of experience in nursing $\left(\mathrm{X}^{2}=20.89\right.$, $\mathrm{p}=0.0001)$, years of experience in care of port-a-cath $\left(\mathrm{X}^{2}=23.48\right.$, $\mathrm{p}=0.0001)$, previous training courses $\left(\mathrm{X}^{2}=55.47, \mathrm{p}=0.0001\right)$. On the other hand, there was no significant correlation between the total knowledge level and gender $\left(\mathrm{X}^{2}=2.94, \mathrm{p}=0.08\right)$.

\section{Discussion}

The aim of this study was to assess oncology nurses' knowledge regarding implantable port catheter care The findings of the current study covered the following sections; distribution of the studied sample in relation to their knowledge about implantable Port-a-cath care and the relationship between nurses' knowledge level and their demographic characteristics.

In relation to the oncology nurses' educational qualifications, the current findings revealed that two-thirds of the studied sample had a bachelor degree and the rest of them had a technical institute degree. This study was in an agreement with the study done by Barnes, et al. who studied physician and nurse beliefs of phase 1 trials in pediatric oncology and found that the majority of the studied sample were had a bachelor degree [10].

The present study sought to assess the oncology nurses' knowledge regarding insertion and care of port-a-cath. it revealed that the total mean knowledge score of the studied nurses was $40.31+2.12$ out of 50 . The possible explanation for this finding that nearly two thirds of the study subjects received previous in-service training courses regarding port-a-cath care. The current study finding was congruent with a similar study done by Özden and Calis, kan who conducted a study entitled "Turkish nurse's level of knowledge regarding implantable port catheter care" that revealed the mean knowledge score of the nurses regarding implantable port catheter care was $15.13+4.78$ out of 20 [11]. Moreover, the difference between the knowledge scores, based on whether or not the nurses had received in-service training, was found to be statistically significant $(\mathrm{p}=0.029)$.

In the same line, the current study finding agreed with Deshmukh and Shinde who studied the impact of Structured Education on Knowledge and Practice Regarding Venous Access Device Care among nurses revealed that the experimental group's mean score of knowledge was increased from 14.6 to 21.3 in the post-test after structured program [12]. It indicated that the structured education is effective in increasing the knowledge scores of subjects regarding venous access device care.

Although most of the nurses have got satisfactory knowledge regarding indication, contraindication of port-a-cath, nearly a quarter of the studied sample revealed a deficiency in nurses' knowledge regarding the definition of port-a-cath, and port-a-cath insertion regulation.

The researcher considers that knowledge is inadequate because most of them have got previous training courses. The current finding was consistent partially with Pires and Vasques entitled "nurse's knowledge regarding the handling of the totally-implanted venous access device" who mentioned that their knowledge regarding the implanted port is inadequate and concluded, therefore, that there is an urgent need for professional training [13]. Although studies regarding the complications that are related to the implantable port catheter are encountered in the literature, there exists no study that aims to 
Citation: Khalil NS, Youssef W, Moustafa Z (2017) Oncology Critical Care Nurse's Knowledge about Insertion, Care and Complications of Venous Port Catheters in Egypt. Adv Practice Nurs 2: 137. doi:10.4172/2573-0347.1000137

Page 5 of 5

measure the knowledge levels of nurses about these complications [14-17]. Consequently, education about implantable port catheter care does not exist in the curricula of all undergraduate nursing programs in Egypt.

In the present study, the researcher studied the relationship between the socio-demographic characteristics of oncology nurses and their total knowledge level. It revealed high significant correlation between nurses' total knowledge and their demographic characteristics except gender. This finding was agreed partially with (Arslan et al.) who found nurses' age had no relationship with their knowledge about port-acatheter and increasing experience in years of practice had a positive relationship with success in testing knowledge [18]. Similarly, our study finding was consistent with Anderson et al. and Ibrahim who mentioned that there was statistically relation between sociodemographic characteristics of the study sample and their total score of knowledge, while no significant correlation between gender of the study sample and their knowledge $[19,20]$.

\section{Conclusion}

The findings of this study proved the majority of oncology nurses' had a satisfactory knowledge level regarding insertion and care of porta-cath. Moreover, their total knowledge relates to their demographic characteristics except gender.

\section{Recommendations}

Assessment of the educational process to identify adequate knowledge and practice of port-a-cath. Continuous educational sessions to improve oncology nurses' clinical practices and knowledge for Port-a-cath. Adding this subject to nursing curriculum will give more awareness to the nurses at the beginning of their carrier. Further research on a larger scale to validate these findings and to determine if nurses' knowledge of port-a-catheters is sufficient to maintain safety and optimal patient care

\section{References}

1. Vescia S, Baumgartner AK, Jacobs VR, Kiechle-Bahat M, Rody A, et al (2008) Management of venous port systems in oncology: A review of current evidence. Ann Oncol 19: 9-15.

2. Barnacle A, Arthurs OJ, Roebuck D, Hirons MP (2008) Malfunctioning central venous catheters in children: A diagnostic approach. Pediatr Radiol 38: 363-378.

3. Kawamura J, Nagayama S, Nomura A, Itami A, Okabe H, et al. (2008) Long-term outcomes of peripheral arm ports implanted in patients with colorectal cancer. Int J Clin Oncol 13: 349-354.

4. Arul GS, Lewis N, Bromley P, Bennett J (2009) Ultrasound-guided percutaneous insertion of hickman lines in children. Prospective study of 500 consecutive procedures. J Pediatr Surg 44: 1371-1376.
5. Sheppard K, Ledesma MM, O'connor K, Morris NL (2009) A prospective study of two intravenous catheter securement techniques in a skilled nursing facility. J Intra Nurs 22: 151-156.

6. Elkhoury MI, Boeckx WD, Chahine EG, Feghali MA (2008) Retrieval of Port-A Catheter fragment from the main and right pulmonary arteries 3 years after dislodgment. J Vasc Access 9: 296-298.

7. Camins BC, Richmond AM, Dyer KL, Zimmerman HN, Coyne DW, et al. (2010) A crossover intervention trial evaluating the efficacy of a chlorhexidine impregnated sponge In reducing catheter related bloodstream infections among patients undergoing hemodialysis. Infect Control Hosp Epidemiol 31:1118-1123.

8. Mushani-Kanji T, Cummings-Winfield C (2008) Restoring patency to central venous access devices. Clin J Oncol Nurs 12: 925-934.

9. Burns N, Grove SK (2005) The practice of nursing research: Conduct, critique, and utilization.

10. Barnes MJ, Pressey J, Adams J, Hensler MA, Swain MA (2014) Physician and nurse beliefs of phase 1 trials in pediatric oncology. Cancer Nurs 37: 48-52.

11. Ozden D, Caliskan N (2012 ) Turkish nurses' level of knowledge regarding implantable port catheter care. Jpn J Nurs Sci 9: 1-8.

12. Deshmukh M, Shinde M (2012) Impact of structured education on knowledge and practice regarding venous access device care among nurse. International Journal of Science and Research 2319-7064.

13. Pires NN, Vasques IC (2014) Nurses' knowledge regarding the handling of the totally-implanted venous access device. Text Context Nursing 23: 443-450.

14. Biffi R, de Braud F, Orsi F, Pozzi S, Mauri S, et al. (1998) Totally implantable central venous access ports for long-term chemotherapy. Ann Oncol 9: 767-773.

15. Biffi R, Pozzi S, Agazzi A, Pace U, Floridi A, et al. (2004) Use of totally implantable central venous access ports for high-dose chemotherapy and peripheral blood stem cell transplantation: Results of a monocentre series of 376 patients. Ann Oncol 15: 296-300.

16. Kreis H, Loehberg CR, Lux MP, Ackermann S, Lang W, et al. (2007) Patients' attitudes to totally implantable venous access port systems for gynecological or breast malignancies. EJSO 33: 39-43.

17. Schwarz RE, Groeger JS, Coit DG (1997) Subcutaneously implanted central venous access devices in cancer patients: a prospective analysis. Cancer 79: 1635-1640.

18. Arslan M, Yalçın S, Kesik F, Demirci B, Balçık SO (2014) Turkish nurses' knowledge about application, care, and complications of peripheral and central venous catheters and port catheters. NERP 4: 11-16.

19. Anderson M, Ottum A, Zerbel S, Sethi A, Safdar N (2013) Are hospitalized patients aware of the risks and consequences of central lineassociated bloodstream infections? Am J Infect Control 41:1275-1277.

20. Ibrahim NK (2015) Assessment of parent and children satisfaction about primary nursing care assessment in children cancer hospital (Cch) 57357, Submitted in partial fulfillment of the requirements for master degree in pediatric nursing sciences, Diane Pravikoff, RN, Phd, Faan, Clinical Information Systems, Glendale, Ca, March 6. 